\title{
DERRIDA E A TRAGÉDIA: O QUASE-CONCEITO DE LUTO EM ANTÍGONA
}

\author{
Bianca Vilhena Campinho Pereira
}

\begin{abstract}
Resumo: Em Espectros de Marx, Derrida menciona Hamlet e diz que não falará de outra coisa senão do luto. Antígona não é mencionada nesta obra, porém resolvemos incluí-la em nossa análise, pois, se Derrida, tratando do luto, menciona a tragédia de Hamlet, a trama da peça de Sófocles circula de modo bem claro em torno do tema. Com o objetivo de abordar e elucidar o quaseconceito ou indecidível de luto derridiano, decidimos fazer uma análise das peças Édipo rei, Hamlet e, sobretudo, de Antígona, a partir do quase-conceito.
\end{abstract}

Em Espectros de Marx, Derrida diz que não falará de outra coisa senão do luto' e, além de mencionar, obviamente, Marx e o marxismo, menciona inúmeras vezes Hamlet. Somos levados assim a afirmar que, segundo o filósofo, a tragédia de Hamlet é, por excelência, a tragédia do luto. O luto, segundo Derrida, é, para além da lógica opositiva, tudo o que há, em nome da vida e em nome da morte.

"Viver, por definição, isto não se aprende. Não por si mesmo, da vida pela vida. Somente do outro e pela morte. Em todo caso, do outro no limite da vida. Tanto no limite interno quanto 
no (limite) externo, trata-se de uma heterodidática entre vida e morte." 2

Somos então seres enlutados. Hamlet, porém, não denega esta condição de modo a obliterá-la, como se nota na batalha especular que trava com seu tio e detentor do trono, que quer interrompê-lo em seu trabalho. Em Antígona, esta é também a tragédia de Creonte, a tragédia daquele que fala em nome da vida e que, presumindo saber o que ela é, procura convencer-se de que o morto não existe mais. A peça Antígona não é mencionada em Espectros de Marx, porém resolvemos incluí-la em nossa análise acerca do luto, pois, se Derrida, tratando do luto, menciona a tragédia de Hamlet, o enredo da peça de Sófocles circula de modo bem claro em torno do tema. Entretanto, para chegarmos até Antígona precisamos atravessar, como que entre o futuro e o passado, as tragédias Édipo rei e Hamlet, bem como o que podemos alcançar do que Shakespeare é herdeiro de Sófocles. Compondo uma análise destas três peças a partir do indecidível de luto - o luto, por um lado, como algo aporético e, por outro, como algo sempre denegado - acreditamos ser possível, além de elucidar melhor o quase-conceito tão caro ao pensamento derridiano e à desconstrução, compreender as questões éticas, políticas e jurídicas que a desconstrução suscita. Para tal, relacionaremos ainda o tema do luto à primeira parte de Força de lei, onde o filósofo evoca a tarefa da desconstrução como aquela de uma responsabilidade incalculável diante da memória e da herança. Para sermos fiéis à desconstrução, é importante mencionar ainda que as obras que nos foram legadas e das quais iremos tratar, a maneira do que é espectral, não permitem clausura e, portanto, desafiam sempre e não deixarão, através dos tempos, de desafiar.

\section{A tragédia, o espectro e a herança}


Na Grécia arcaica, o destino do rei está intrinsecamente relacionado com o destino da comunidade e, na Grécia clássica do teatro a tragédia não foge a esta sina. Em Édipo rei, quando Laio é morto, Tebas seria infestada por uma peste avassaladora se não fosse Édipo, o decifrador de enigmas, a calar a Esfinge. A epidemia, no entanto, anos depois chegará exigindo a expiação do crime perpetrado contra o antigo rei. $O$ inquérito/auto-descoberta de Édipo se inicia quando ele pede conselho ao oráculo sobre como acabar com o flagelo que devastava Tebas. A mensagem do oráculo de Apolo diz que somente com a expiação do crime cometido contra o antigo rei, pela morte ou banimento do ser impuro, à peste seria posta um fim.

Édipo, como governante, precisa encontrar uma forma de pôr fim a este mal e, ao descobrir a si mesmo como o assassino de Laio, é condenado pelo seu próprio edito ao banimento da cidade. Antes disso, porém, cega os próprios olhos. De alguma maneira, fomos todos cegados por Édipo, mas se Édipo nos deixou de herança a cegueira, apenas alguns podem entrevê-la. Em Édipo tudo se passa como se de um sonho ocorresse um salto a um estado de vigília excessiva, a visão que é cega pela luz. Em Hamlet, só os que dormem podem ver. "Morrer- dormir - Dormir! Talvez sonhar. Aí está o obstáculo! Os sonhos que hão de vir no sono da morte quando tivermos escapado ao tumulto vital nos obrigam a hesitar: e é essa reflexão que dá à desventura vida tão longa." 3 Segundo Derrida, Hamlet pragueja contra o infortúnio de ter nascido para castigar, vingar, exercer a justiça e o direito. Matar para viver. Hamlet é chamado pelo espectro de seu pai para endireitar o mundo, colocá-lo em seus eixos, em seu reto caminho, vingar-se do tio pelo assassinato do pai, missão esta que, segundo Derrida, o príncipe amaldiçoa por ser-lhe inata, "dada pelo seu nascimento, assim como ao seu nascimento." 4 Édipo, por seu turno, 
definindo orgulhosamente sua vitória sob a Esfinge como obra apenas de sua inteligência e esforço, é um homem de ação. O filho de Laio afirma, no entanto, que não foi despertado apenas agora do seu sono, mas que, ao contrário disso, já derramou copiosas lágrimas na errância de seu pensamento, e que lhe veio à mente apenas a solução de consultar o oráculo. A partir desta decisão que o levará a perdição, nenhuma passividade interpor-se-á em sua ação, mas, ao contrário, sempre irá impor-se sobre as pessoas e as circunstâncias, desdenhando sempre da inatividade.

De acordo com Derrida:

\begin{abstract}
"Só há tragédia, só há essência do trágico desde que haja essa originariedade, mais precisamente, essa anterioridade préoriginaria e propriamente espectral do crime. Do crime do outro, um crime grave cujo acontecimento e a realidade, e a verdade, não podem nunca apresentar-se em carne e osso; podem apenas se deixar presumir, reconstruir, fantasmar." 5
\end{abstract}

Hamlet, conforme afirma Derrida, amaldiçoa o destino que o teria destinado a ser o homem do direito. Justamente como se amaldiçoasse o direito mesmo que teria feito dele um reparador de erros, aquele que não pode vir, como o direito, senão após o crime. Édipo, por sua vez, cega os próprios olhos porque vê ao mesmo tempo o crime e a reparação do crime serem praticados pelo mesmo homem. Édipo, apesar de ignorante da identidade de sua vítima, mata quem lhe deu a vida, na mesma travessia em que tentava escapar de seu destino vaticinado. Édipo declara que em uma encruzilhada de três caminhos, ele mesmo, um homem só, possivelmente tenha matado toda a comitiva do rei. Contudo, neste momento da investigação surge uma esperança devido a uma discrepância numérica entre os relatos da morte de Laio, pois Jocasta afirmara que, segundo o pastor, os assassinos foram vários. 
Interessante neste ponto notar o que diz Derrida em Espectros de Marx sobre o espectro. Nem alma nem corpo, e uma e outra, o espectro possui uma estranha forma de aparição e desaparição, e, sem que se possa assegurar o que ele tem em comum com o espírito, pois sendo pura dispersão, sem reunião possível, há dificuldade em identificar se ele é mais de um ou menos de um. ${ }^{6}$ Derrida afirma a necessidade de falar do e com o fantasma, e, segundo ele, apenas a singularidade de uma posição de fala, de uma experiência e de um lugar de filiação são lugares e laços a partir dos quais podemos nos dirigir ao fantasma, apenas quem sente e suporta uma inadequação a si é capaz de falar ao fantasma e fazê-lo falar. "O tempo está fora dos eixos. Pobre de mim que nasci para pô-lo novamente no lugar." 7 É necessário, em um tempo sem junção assegurada nem conjunção determinável, alguém bastante louco para dar livre curso a possibilidade de tal endereçamento. E o filósofo nos encaminha a questão: e se o desajuste fosse a condição da justiça? ${ }^{8}$

Em Força de lei, Derrida afirma que ser fiel ao chamado da desconstrução corresponde a um duplo movimento: uma postura de constante vigilância e desconfiança em relação aos pontos fixos que organizam o pensamento, mantendo um questionamento sobre os fundamentos e os limites de nosso aparelho teórico e normativo em torno da justiça; e uma responsabilidade diante do próprio conceito de responsabilidade, pois este regula a justeza de todas as nossas decisões. 9 Em Espectros de Marx, Derrida propõe que pensemos a tragédia irreparável, a maldição indefinida que caracteriza a história do direito, e assume que o porvir só pode ser preservado pela abertura da heterogeneidade, ou seja, não pode ser senão dos fantasmas. Para o filósofo, estar com os espectros seria, pois, uma política da memória, da

6

Ibidem, p. 21.

Shakespeare. Hamlet, ato I, cena 5.

Derrida J. Espectros de Marx: o estado da dívida, o trabalho do luto e a nova Internacional, p.

Derrida J. Força de lei: o fundamento místico da autoridade, p. 37. 
herança e das gerações; e a justiça só se preserva possível pelo reconhecimento desses outros que não estão mais e dos que ainda não estão.

O fantasma, por um lado, volta, ou seja, evita a conjuração que se faz para erradicá-lo, mas, por outro, ele aparece justamente para que o deixe ir. A herança, deste modo, é identificada ao trabalho que se dá nesta indecidível fronteira, pois ela é sempre e ao mesmo tempo "um imperativo e um feixe de injunções." ${ }^{10} \mathrm{~A}$ herança, portanto, é um segredo, e o herdeiro deve responder a essa dupla injunção, contraditória (mas complementar), que é, por um lado, afirmar o que vem antes e a necessidade de apropriar-se de um passado que é inapropriável, e, por outro, após a decisão de dizer 'sim', selecionar, filtrar, ou seja, transformar. " O desejo de conservar o morto, encerrá-lo como memória, mostra o processo de introjeção e de interiorização do outro, isto é, ao apropriar-se do outro, idealizá-lo para conservá-lo, perde-se aquilo que o faz outro. No entanto, o desejo de deixar ir o morto indica um respeito a sua alteridade em sua impossível redução para, desta maneira, continuar sendo por ele instigado. Diferente do luto que tem um fim e, portanto, que pretende negar o outro dele apropriando-se, o luto impossível derridiano quer a manutenção do outro em mim, como alteridade. A tarefa que carrega consigo a angústia da suspensão, intervalo ou aporia necessária que abre para o porvir e as transformações, é cara à desconstrução, que se opondo a qualquer ideal de totalidade, de identidade e de retorno à origem, vê no luto a capacidade de suportar a aporia. Se Hamlet, portanto, é um ser enlutado e que sente essa condição, ele é também herdeiro de Édipo, daquele que cega os próprios olhos porque sua visão foi excessiva.

\section{O luto de Antígona (ou quase-luto)}

Ibidem, p.37.

Derrida J. De que amanhã: diálogo Jacques Derrida; Elisabeth Roudinesco, p.13. 
O núcleo da trama da peça de Sófocles, Antígona, é a morte e o sepultamento de Polínices, traidor de Tebas e filho de Édipo. De um lado está Creonte, o representante do Estado que proíbe o sepultamento do morto, argumentando que o morto, sendo um traidor da pátria, não merece as honras funerárias. Da perspectiva de um chefe de Estado, Creonte defende a pátria, zela pela unidade e os interesses da polis, afirmando que só quem quiser o bem de Tebas terá a sua estima, tanto em vida quanto em morte. Do outro lado está Antígona, irmã do morto, que insiste que sejam concedidas as honras funerárias ao irmão e defende, da perspectiva de parente e amiga dos mortos, como ela mesma se diz ${ }^{12}$, a importância de que o morto seja sepultado e honrado. A peça de Sófocles apresenta uma aporia, uma vez que, por um lado, é legítimo que haja lei, bem como é legitima a contraposição que lhe faz a heroína. Em cena, portanto, a peça coloca o problema da punição (com a morte) ao descumprimento do edito do rei, abordando paralelamente a questão do luto e da denegação do luto.

A figura de Antígona parece ser a própria encarnação do 'tempo fora dos eixos.' Diferente de Hamlet em seu 'ser ou não ser, fazer ou não fazer', Antígona abraça a morte e sem hesitar vai ao encontro dos seus que estão no Hades. Sua solidão e força para a ação misturam-se com algo que a faz ligada de modo extremo a sua linhagem familiar: as leis novas, as leis da cidade não parecem lhe interessar. Antígona, tal como afirma Derrida a respeito do espectro, não nos permite saber se "testemunha retornando de um vivo passado ou de um vivo futuro, pois a heroína, ao mesmo tempo em que é herdeira da linhagem amaldiçoada, a faz cessar. Ao abraçar as leis antigas e insurgir-se contra a arbitrariedade de um novo, ela contribui para romper com a maldição familiar, uma vez que ela abdica de casar e perpetuar a linhagem dos Labdácios. Antígona inclusive nega Ismene, sua irmã, pelo seu tipo submisso, como descente de Cadmo, chamando a si mesma de a última filha da casa real 
- e essas são as suas últimas palavras. É, portanto, Antígona, em sua irrupção, ainda no interior de sua própria herança maldita, que interrompe a maldição dos descendentes de Cadmo. Talvez neste ponto ambos os heróis, Antígona e Creonte, estejam secretamente de acordo: acabar com a linhagem amaldiçoada. Porém, se a partir daí abre-se o caminho para o surgimento de um homem mais individualizado e cidadão da cidade, menos fechado em seu círculo familiar, mais responsável diante da cidade e de seus próprios atos, a armadilha está justamente aí. Ao perdermos ou ao supormos que perdemos a maldição familiar - com o objetivo de interromper os ciclos intermináveis de vingança que recheavam a mitologia e o cotidiano da Grécia - ganhamos a maldição do direito. Esta maldição é sugerida pelo próprio Derrida, "uma maldição inscrita no próprio direito em sua origem assassina." 13

Creonte é aquele que não pode vir, como o direito, senão após o crime. Herdeiro reparador de erros, o rei, que julga possuir a cidade e que se confunde com a cidade que governa, cai na armadilha. Creonte, o que fala em nome da vida, o que se empenha em constatar a morte, em silenciar a morte, censura severamente Antígona em seus lamentos afirmando a inutilidade de chorar o que não tem solução e louva a celeridade necessária nas decisões de um rei. ${ }^{14}$ Hamlet, o príncipe desajustado, é atravessado pela retidão que o quer impelido, sem desvio, ao caminho reto do direito, e amaldiçoa o seu destino que é consertar um tempo que anda de revés, um destino que o impele a endireitar as coisas e a sorte que lhe destinou a recolocar nos eixos um mundo desconjuntado. Édipo, por sua vez, cega os olhos ao ver a si mesmo como o criminoso que tão arduamente procurava ao tentar fazer justiça, vingar a morte de Laio e trazer de volta o ajuste para a cidade transtornada e desregrada pela peste. Ele descobre que, em sua união incestuosa, o tempo está fora dos eixos e que o semeador é também a semente. Em Édipo rei, Édipo é chamado através 
do oráculo trazido por Creonte a solucionar o crime e ajustar a cidade. Em Antígona, é Creonte, por consequência de seu próprio edito, que infunde enfermidade à Tebas, e a notícia disto é trazida pelo profeta Tirésias que a tem revelada pelo voo das aves. As aves já não mais emitiam sinais claros e se dilaceravam umas às outras por terem provado o sangue do insepulto.

Derrida não nega, mas afirma a necessidade de que haja lei, questiona, contudo, a pretensão do direito como o lugar da justiça. $O$ filósofo, ao problematizar a partir da contraposição entre a força que é legitimada e a força que não é legitimada, mostra que, se a força é aplicada no direito, a justiça só pode ser algo que excede o direito. Será que é possível uma justiça que esteja para além do direito, para além da vingança, uma injunção do espectro que não passe pelo assassinato? O pensamento da Desconstrução afirma a justiça como incalculabilidade, a única capaz de afirmar a singularidade do outro. Em Espectros de Marx, Derrida pergunta incessantemente pela possibilidade em se ultrapassar a lógica da reparação pela vingança e pelo direito. Em Força de lei, ele nos remete à estranheza de perceber a justiça como uma experiência impossível, incalculável, promovendo um descolamento, distinguindo e separando direito e justiça, dando ao primeiro um caráter ordinário, calculável, e, à segunda, um caráter extraordinário, incalculável. ${ }^{15}$ Neste ponto é importante enfatizar que muito mais do que colocar uma oposição entre indecidibilidade e decisão, o que Derrida faz é chamar atenção para o problema da responsabilidade cuja premissa não seja a aplicação de uma regra ou algo programável, ou seja, destituído de responsabilidade, pois, só onde há indecidibilidade, há de fato necessidade de decisão, e, portanto, responsabilidade.

Segundo o filósofo, é preciso a disjunção, a interrupção, o heterogêneo para se dar chance a qualquer injunção ou, em outras palavras, a traduzibilidade assegurada, a homogeneidade dada, erradicam toda a possibilidade da herança e do porvir. Neste sentido, o espectro é aquilo que 
dessincroniza e faz-nos voltar a anacronia. Quando Derrida se pergunta pela possibilidade de um fazer justiça que não se limitaria a sancionar e a compensar um erro e restituir um débito, mas dar, doar para a além do dever e da dívida, temos Hamlet em sua hesitação em vingar, em sua nãoautomaticidade do cálculo, em seu estar fora dos eixos, como rastro. No caso de Antígona, é interessante notar que a automaticidade de sua ação é sem cálculo, ela calcula com o incalculável. Sua desmesura vem simultaneamente do porvir e do passado e sua desproporção se dirige à singularidade e precedência do outro, no caso, o seu irmão, em relação ao qual não tem propriamente uma dívida, mas cuja demanda e proximidade não pode ser negada, tampouco, anulada.

Se por meio da aporia assinalada por Derrida, a análise da peça Antígona não merece uma oposição marcada que prioriza Antígona como detentora da justiça insurgindo-se contra o tirano, o gênio de Sófocles marca, sim, uma oposição. Creonte fala em nome da vida e presume saber o que ela é; Antígona se diz amiga dos mortos, nega os deuses Dioniso e Afrodite, os deuses da renovação. Antígona, por ordens de Creonte, é confinada viva em uma caverna pelo preço de ter, segundo as palavras do rei, amado mais aos mortos do que aos vivos. Não obstante a desmedida de Antígona, não podemos deixar de admirá-la em sua hybris. Tocada por uma espécie de dever incomunicável, à escuta das leis não escritas, das leis divinas que não foram postas pelos deuses, mas que vigem desde tempos imemoriais, ${ }^{16}$ ela escolhe a morte, mas ao fazer essa escolha, escolhe a vida, ela inclui a morte na vida. "Como serei desventurada ali, nem pertencendo aos vivos, nem aos mortos," 17 lamenta ela. A força das determinações de Creonte, afirma Antígona, não foi suficiente para impor a todos os mortais a obrigação de transgredir normas divinas e perenes. $O$ que se revela pelos interstícios do seu excesso e 
desproporção é uma sensibilização hiperbólica à justiça, sua desproporção se dirige à singularidade e precedência do outro, anunciando-se, portanto, como afirmação do porvir. Antígona, como sua irmã mesma o diz, ama o impossível. O luto é a afirmação do impossível e esta é a herança que Antígona nos deixa. Herança que é, como o luto, um trabalho.

\section{Bibliografia}

DERRIDA, Jacques. Espectros de Marx: o estado da dívida, o trabalho do luto e a nova internacional. Rio de Janeiro: Relume Dumará, 1994.

Força de Lei: o fundamento místico da autoridade. São Paulo: Martins Fontes, 2007.

De que amanhã: diálogo Jacques Derrida; Elisabeth Roudinesco. Rio de Janeiro: Jorge Zahar, 2004.

Duque-Estrada, Paulo Cesar (Org.). Desconstrução e Ética. Ecos de Jacques Derrida. Rio de Janeiro: Ed. PUC-Rio; São Paulo: Loyola, 2004.

SHAKEASPEARE, William. Hamlet. Porto Alegre: L\&PM, 2013.

SÓFOCLES. A Trilogia Tebana. Tradução: Mario da Gama Cury. Rio de Janeiro: Jorge Zahar, 1993. 